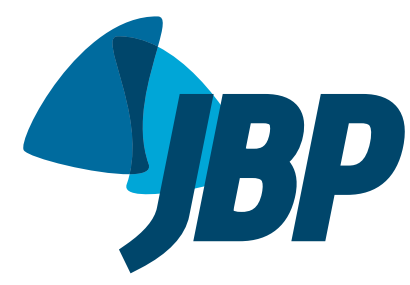

1. Disciplina de Pneumologia, Universidade Federal de São Paulo - UNIFESP - São Paulo (SP) Brasil.

Submitted: 21 September 2016. Accepted: 10 July 2017.

Study carried out in the Disciplina de Pneumologia, Universidade Federal de São Paulo - UNIFESP - São Paulo (SP) Brasil.

\section{Survival in a cohort of patients with lung cancer: the role of age and gender in prognosis}

\author{
Juliana Pereira Franceschini1', Sérgio Jamnik¹, Ilka Lopes Santoro
}

\begin{abstract}
Objective: To determine the demographic and clinical characteristics of patients with non-small cell lung cancer (NSCLC), as well as their disease course, by age group and gender. Methods: This was a retrospective cohort study of patients diagnosed with NSCLC from 2000 to 2012 and followed until July 2015 in a tertiary referral hospital in the city of São Paulo, Brazil. Based on the 25th and 75th percentiles of the age distribution, patients were stratified into three age groups: $<55$ years; $\geq 55$ and $<72$ years; and $\geq 72$ years. Survival time was evaluated during the follow-up period of the study. Functions of overall and gender-specific survival stratified by age groups (event: all-cause mortality) were calculated using the Kaplan-Meier method. Differences among survival curves were assessed via the log-rank test. Results: We included 790 patients with the following age distribution: < 55 years, 165 patients; $\geq 55$ and < 72 years, 423; and $\geq 72$ years, 202. In the entire sample, there were 493 men (62.4\%). Adenocarcinoma was the most common histological pattern in the $<72$-year age groups; 575 patients (73\%) presented with advanced disease (stages IIIB-IV). The median 5 -year survival was 12 months (95\% Cl: 4-46 months), with no significant differences among the age groups studied. Conclusions: NSCLC remains more common in men, although we found an increase in the proportion of the disease in women in the $<55$-year age group. Adenocarcinoma predominated in women. In men, squamous cell carcinoma predominated in the $\geq 72$ year age group. Most patients presented with advanced-stage disease at diagnosis. There were no statistical differences in survival between genders or among age groups.

Keywords: Lung neoplasms; Age groups, Sex; Survival.
\end{abstract}

\section{INTRODUCTION}

Changes in the demographic structure of the Brazilian population indicate a process of population aging. According to data from the Brazilian Institute of Geography and Statistics, the proportion of elderly individuals increased from $7.2 \%$ in 2000 to $11.7 \%$ in 2015 , currently consisting of a contingent of more than 23 million people. ${ }^{(1)}$ The demographic transition results in an epidemiological transition, which means that the population's disease profile has changed to that of chronic diseases.

In Brazil, as well as in other countries in the world, lung cancer remains an elderly disease. ${ }^{(2-4)}$ The proportion of lung cancer patients aged 50 or younger is estimated to be at most $12 \% .{ }^{(5-9)}$ In addition, lung cancer has ceased to be an almost exclusively male disease and has become increasingly common among women. Furthermore, this neoplasm occurs more frequently in patients with a history of smoking, and the closing gap in smoking rates between men and women is one of the contributing factors to the increase in the incidence of lung cancer in women. ${ }^{(10)}$

There are few studies in the literature that have evaluated the course of non-small cell lung cancer (NSCLC) by age group and gender. Therefore, the objective of the present study was to determine the major demographic and clinical characteristics of patients with NSCLC, as well as their disease course, by gender and age group.

\section{METHODS}

This was a retrospective cohort study nested within a structured database (which is part of a hospital tumor registry) and involving lung cancer patients followed in a tertiary referral hospital in the city of São Paulo, Brazil. The present study was approved by the local research ethics committee, and all patients gave written informed consent at the time of their entry into the database.

The start data of observation was January 1, 2000, and the deadline for inclusion of new cases in the cohort was July 31, 2012; for the purpose of the study, patients were followed until July 31, 2015. We included all patients with a histologically and cytologically proven diagnosis of NSCLC who were treated in the aforementioned hospital. At the time of diagnosis, data on demographic and clinical variables, such as age, gender, functional status (as measured by the Karnofsky performance status), smoking status (never vs. current or former smoker), and smoking history (in pack-years) were collected, as were data on tumor-related variables, such as histological type (adenocarcinoma, squamous 
carcinoma, other), stage (IA-IIIA vs. IIIB-IV), and presence of site-specific metastasis, categorized as intrathoracic or extrathoracic.

Based on the 25th and 75th percentiles of the age distribution, patients were stratified into three age groups: $<55$ years; $\geq 55$ and $<72$ years; and $\geq 72$ years. Survival time, defined as the time between the date of histological diagnosis and the date of the last event, was recorded during follow-up. A last event was defined as all-cause mortality (date of death), as the patient being alive at the end of the study follow-up, or as the patient being lost to follow-up-this patient was censored at the last date of contact.

Data are expressed as mean \pm SD or as median (interquartile range). Categorical variables were analyzed with the chi-square test or Fisher's exact test, and numerical variables were analyzed using one-way ANOVA (complemented by the Bonferroni test) or the Kruskal-Wallis test (complemented by Duncan's test) depending on the sample distribution. Functions of overall and gender-specific survival stratified by age group were calculated using the Kaplan-Meier method. Differences among survival curves were assessed via the log-rank test. Test results with an a error $<5 \%(p<0.05)$ were considered significant. Data were analyzed with the Statistical Package for the Social Sciences, version 17.0 (SPSS Inc., Chicago, IL, USA).

\section{RESULTS}

During the study inclusion period, we identified 790 patients with a diagnosis of NSCLC, 493 (62.4\%) of whom were male and $297(37.6 \%)$ of whom were female. The mean age of the entire study sample was $64 \pm 11$ years, ranging from 27 to 93 years. It is important to emphasize that the female gender had a lower median age and a lower 25th percentile than those of the male gender (62 and 54 vs. 66 and 58 years, respectively). In addition, we observed that $10 \%$ of women were less than 50 years of age at the time of diagnosis, whereas only $5 \%$ of men were in the youngest age group. Figure 1 illustrates the distribution of the 790 patients studied, divided by gender, in relation to age percentiles.

Male patients predominated in all age groups studied; however, the female/male ratio was highest in the youngest age group, and this difference was statistically significant ( $p=0.012$; Table 1 ).

Although the median Karnofsky performance status was the same for the three age groups, the $\geq 72$-year age group had a lower proportion of patients with Karnofsky performance status above the median than did the other age groups ( $p=0.007$; Table 1 ).

Smoking was confirmed in 664 (84\%) of the cases evaluated, with 462 men (94\%) and 202 women (68\%) being smokers. There was a predominance of smokers among male patients for all age groups. In addition, the female/male ratio of smokers increased inversely

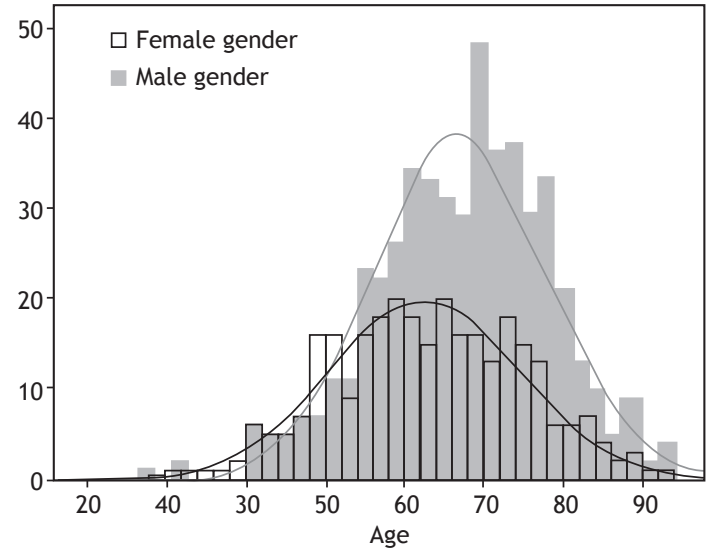

\begin{tabular}{|c|c|c|c|c|c|c|c|}
\hline \multirow{2}{*}{ Gender } & \multicolumn{7}{|c|}{ Percentile } \\
\cline { 2 - 8 } & 5 & 10 & 25 & 50 & 75 & 90 & 95 \\
\hline F & 42.00 & 47.80 & 54.00 & 62.00 & 72.00 & 77.20 & 83.00 \\
\hline M & 47.00 & 52.00 & 58.00 & 66.00 & 72.00 & 77.00 & 81.00 \\
\hline
\end{tabular}

Figure 1. Age percentile distribution, by gender, for the 790 patients studied.

proportionally to increasing age group; however, this difference did not reach statistical significance (Table 1).

The median smoking history of the entire sample was 45 pack-years (interquartile range: 30-63 pack-years), with patients in the $\geq 72$-year age group having a higher mean smoking history than those in the other age groups $(p<0.001)$. Although women smoked less than men in all age groups, the gender difference in smoking history was lowest in the youngest age group (Table 1).

Adenocarcinoma was the most common histological pattern for individuals aged 71 or younger, although this difference did not reach statistical significance (Table 1). In the female gender, adenocarcinoma predominated in all age groups, whereas squamous carcinoma predominated in the oldest age group in the male gender. Although there was a predominance of adenocarcinoma among women, regardless of smoking status, the proportion of adenocarcinoma among neversmoking women was higher $(p=0.04)$. In the male gender, there was a predominance of adenocarcinoma among never smokers and a predominance of squamous carcinoma among smokers $(p=0.001)$.

A total of 575 patients (73\%) were found to have advanced NSCLC (stages IIIB-IV). There was no difference in disease stage distribution among the different age groups studied (Table 1). A total of 368 patients $(47 \%)$ did not present with metastasis at diagnosis. The $\geq 55$ - and $<72$-year age group had the highest proportion of patients without metastasis, whereas the < 55-year age group had the highest proportion of individuals with extrathoracic metastasis ( $p<0.046$; Table 1). The most common site of metastasis was the lung, followed by the pleura. Of the extrathoracic sites of metastasis, the brain was the most common. There were no differences in the 
Table 1. Demographic and clinical data of 790 patients with non-small cell lung cancer, by age group. ${ }^{a}$

\begin{tabular}{|c|c|c|c|c|}
\hline \multirow[t]{2}{*}{ Variable } & \multicolumn{3}{|c|}{ Age, years } & \multirow[t]{2}{*}{$\mathbf{p}$} \\
\hline & $\begin{array}{c}<55 \\
(n=165)\end{array}$ & $\begin{array}{c}\geq 55 \text { and }<72 \\
(n=423)\end{array}$ & $\begin{aligned} & \geq 72 \\
\text { (n } & =202)\end{aligned}$ & \\
\hline Male gender & $87(53)$ & $279(66)$ & $127(63)$ & $0.012^{*}$ \\
\hline Karnofsky performance status & $80.7 \pm 14.4$ & $79.9 \pm 14.7$ & $76.4 \pm 15.3$ & $0.007^{\ddagger}$ \\
\hline Smoking & $136(82)$ & $363(86)$ & $165(82)$ & $0.34^{*}$ \\
\hline Male & $78(90)$ & $263(94)$ & $121(95)$ & $0.21^{*}$ \\
\hline Female & $58(74)$ & $100(69)$ & $44(59)$ & $0.10^{*}$ \\
\hline Smoking history, pack-years & $34.7 \pm 22.7$ & $53.3 \pm 30.2$ & $63.4 \pm 41.4$ & $<0.001^{\ddagger}$ \\
\hline Male & $39.1 \pm 24.5$ & $57.8 \pm 28.8$ & $70.7 \pm 42.2$ & \\
\hline Female & $28.9 \pm 18.8$ & $41.6 \pm 30.6$ & $42.2 \pm 31.3$ & \\
\hline Tumor size, $\mathrm{cm}$ & $5.1 \pm 2.6$ & $4.7 \pm 2.5$ & $4.8 \pm 2.3$ & $0.52^{\ddagger}$ \\
\hline Histological type & & & & $0.13^{*}$ \\
\hline Adenocarcinoma & $92(56)$ & $216(51)$ & $91(45)$ & \\
\hline Squamous cell carcinoma & $52(32)$ & $170(40)$ & $91(45)$ & \\
\hline Other & $21(12)$ & $37(09)$ & $20(10)$ & \\
\hline Baseline stage of disease & & & & $0.057^{*}$ \\
\hline IA-IIIA & $34(21)$ & $127(30)$ & $52(26)$ & \\
\hline IIIB-IV & $131(79)$ & $294(70)$ & $150(74)$ & \\
\hline Metastasis at T0 & & & & $0.046^{*}$ \\
\hline MO & $70(42)$ & $213(50)$ & $85(42)$ & \\
\hline M1a & $45(27)$ & $108(26)$ & $71(35)$ & \\
\hline M1b & $50(30)$ & $102(24)$ & $46(23)$ & \\
\hline Deaths & $83(50)$ & $232(55)$ & $105(52)$ & $0.56^{*}$ \\
\hline Follow-up, months & $4.9[1.3-13.2]$ & $6.5[2.0-16.3]$ & 4.4 [1.4-12.9] & $0.07^{\dagger}$ \\
\hline
\end{tabular}

T0: date on which the diagnosis of lung cancer was confirmed; M0: no metastasis; M1a: lung or pleural/pericardial

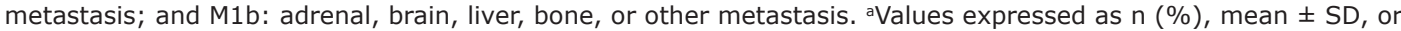
median [interquartile range]. ${ }^{*}$ Chi-square test. ${ }^{\ddagger}$ One-way ANOVA (complemented by the Bonferroni test). ${ }^{\dagger}$ KruskalWallis test (complemented by Duncan's test).

distribution of metastasis sites among the age groups (Table 2).

The median 5-year survival was 12 months (95\% CI: 4-46 months) with a follow-up of at least 3 years (Table 1). There was no significant difference in agegroup specific survival (Figure 2 ). The same was true for gender-specific survival.

\section{DISCUSSION}

Lung cancer is a disease that predominates in elderly individuals, and, according to the literature, its incidence gradually increases with advancing age..$^{(3,11)}$ However, $21 \%$ of the study population were less than 55 years of age at diagnosis, with $10 \%$ of women being less than 50 years of age. Group stratification was based on percentiles of the age distribution rather than on the international definition of elderly, which considers the age of 60 years as a cut-off point for developing countries. The percentile-based cut-off point was chosen because we wanted to adjust the patient group distribution to the particular characteristics of our sample.

The world literature shows that, although most lung cancer patients in all age groups are male, the gender difference in the number of cases is smaller in younger age groups, ${ }^{(12)}$ which corroborates the results of the present study, since the proportion of women was highest in the $<55$-year age group. Similarly, it is known that, in general, young patients with lung cancer are female, are never smokers, predominantly have adenocarcinoma histology, and are diagnosed at an advanced stage of disease. ${ }^{(13)}$

According to the World Health Organization, women currently represent $20 \%$ of smokers worldwide. ${ }^{(14)}$ In the present study, not only was the proportion of female smokers higher in the youngest age group than in the others, but also the gender difference in smoking history was smaller. This is in line with data on smoking in Brazil, which demonstrate that the decline in the number of smokers has been less pronounced among females than males since 1980, when this type of epidemiological research began. ${ }^{(11,15)}$ The decrease in smoking habit observed over the study period was concomitant with national interventions for smoking control, such as pictorial cigarette pack warnings, advertising restriction, laws establishing smoke-free environments, and cigarette price and tax increases. ${ }^{(16,17)}$

Another contributing factor to closing the gap in smoking rates between women and men in the < 55 -year age group is the probable greater difficulty experienced by women in quitting smoking. ${ }^{(18-20)}$ This is probably related both to physical factors, such as the relationship between nicotine and female hormones, and to emotional factors associated with mood and 
affect. In addition, earlier age at smoking initiation and longer-term tobacco consumption translate into greater difficulty in quitting smoking. ${ }^{(11)}$

The increase in smoking among women is one of the factors that may explain the increase in lung cancer mortality in this population. ${ }^{(21,22)}$ In our study, we observed a higher number of women in the < 55 -year age group than in the other age groups. The $<55$-year age group comprised a higher proportion of patients diagnosed with adenocarcinoma. In general, adenocarcinoma is more weakly related to the smoking habit than is squamous carcinoma, ${ }^{(23,24)}$ which was more common in individuals who were older and had a greater smoking history.

There were no differences in survival among the different age groups studied. This may be related to disease stage at diagnosis, which also did not differ among the age groups, with most individuals presenting with either locally advanced or metastatic disease at diagnosis, which is in agreement with the findings reported in the international literature. ${ }^{(25)}$ With regard to metastasis, we found that, in the oldest age group, the prevalence of brain and adrenal metastasis was lower than in the other age groups studied, although there were no significant differences.

International consensus guidelines on cancer treatment are not always applicable to patients in extreme age groups (i.e., young or elderly patients). Therefore, appropriate follow-up of such individuals becomes increasingly important. $(26,27)$ With advancing age, patients are more likely to have comorbidities that may lead to polypharmacy, and, in addition, physiological changes inherent in the aging process may impair renal

Table 2. Distribution of sites of intrathoracic and extrathoracic metastasis for the three groups of patients with nonsmall cell lung cancer, by age group. ${ }^{a}$

\begin{tabular}{|c|c|c|c|c|}
\hline \multirow[t]{2}{*}{ Variable } & \multicolumn{3}{|c|}{ Age, years } & \multirow[t]{2}{*}{ p } \\
\hline & $\begin{aligned}<55 \\
(n=165)\end{aligned}$ & $\begin{array}{c}\geq 55 \text { and }<72 \\
(n=423)\end{array}$ & $\begin{aligned} & \geq 72 \\
(n & =202)\end{aligned}$ & \\
\hline M1a & & & & 0.24 \\
\hline Lung & $23(51)$ & $54(50)$ & $44(62)$ & \\
\hline Pleura/pericardium & $22(49)$ & $54(50)$ & $27(38)$ & \\
\hline M1b & & & & 0.40 \\
\hline Adrenal & $8(16)$ & 17 (17) & $4(9)$ & \\
\hline Brain & $18(36)$ & $38(37)$ & $11(24)$ & \\
\hline Liver & $7(14)$ & 19 (19) & $14(30)$ & \\
\hline Bone & $13(26)$ & $24(24)$ & $14(30)$ & \\
\hline Other & $4(8)$ & $4(4)$ & $3(7)$ & \\
\hline
\end{tabular}

avalues expressed as $\mathrm{n}(\%)$.

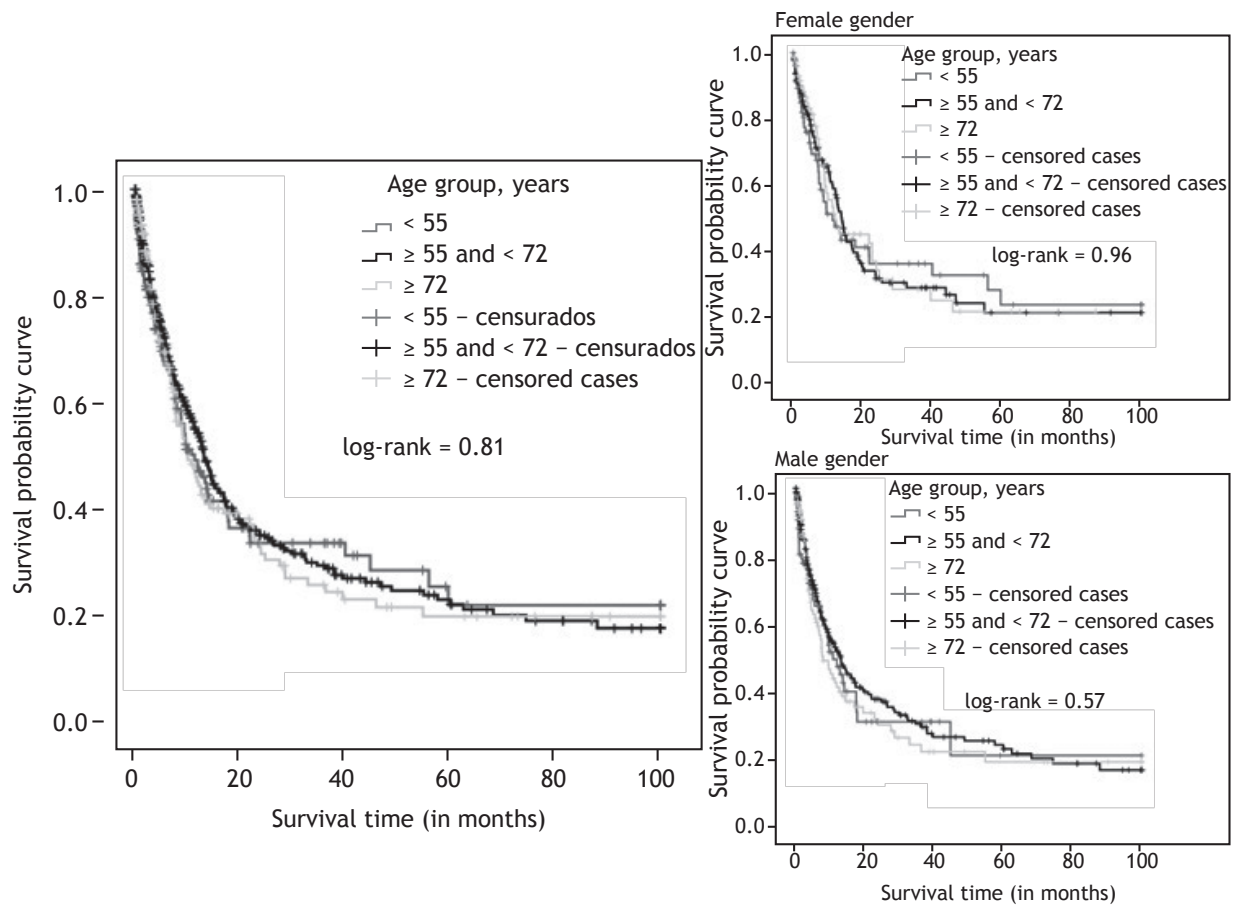

Figure 2. Overall and gender-specific survival probability curves for non-small cell lung cancer patients stratified by age group. 
and hepatic functions, bringing about changes that affect the pharmacokinetics and pharmacodynamics of medications, with a consequent increase in adverse effects associated with chemotherapy treatment. $(3,27)$ In the present study, functional status in the oldest age group, as measured by the Karnofsky performance status, was lower than that in the other age groups, which may be related to the presence of frailty and comorbidities.

The major contribution of the present study is that it described and compared the clinical characteristics of a sample of lung cancer patients of different age groups, with an emphasis on extreme age groups. Among its limitations is the fact that it is a retrospective study conducted in a single tertiary referral center, which may increase the risk of selection bias inherent in the design, with implications for the external validity of the results, although patient inclusion was consecutive. In addition, it was not possible to determine possible comorbidities in the patients by using objective methods, such as the Charlson comorbidity index.

The present study presented the characteristics of lung cancer patients, stratified by age group. On that basis, we conclude that the frequency of NSCLC remains higher among men, although we observed an increase in the proportion of the disease in women in the youngest age group ( $<55$ years) when compared with the other age groups. Adenocarcinoma was the predominant histological type in women. In men, squamous carcinoma predominated in patients $\geq 72$ years of age. Most patients presented with advancedstage disease at diagnosis. There were no statistical differences in survival between genders or among age groups.

\section{REFERENCES}

1. Instituto Brasileiro de Geografia e Estatística [homepage on the Internet]. Rio de Janeiro: Instituto Brasileiro de Geografia e Estatística; [updated 2016 Jan 15; cited 2016 Jan 15]. Projeções e estimativas da população do Brasil e das Unidades da Federação. Available from: http://www.ibge.gov.br/apps/populacao/projecao/ index.html

2. Barros JA, Valladares G, Faria AR, Fugita EM, Ruiz AP, Vianna $A G$, et al. Early diagnosis of lung cancer: the great challenge. Epidemiological variables, clinical variables, staging and treatment J Bras Pneumol. 2006;32(3):221-7. https://doi.org/10.1590/S180637132006000300008

3. Leduc C, Quoix E. Management of lung cancer in elderly [Article in French]. Rev Prat. 2015;65(7):945-9.

4. DeSantis $C E$, Lin $C C$, Mariotto $A B$, Siegel RL, Stein KD, Kramer JL, et al. Cancer treatment and survivorship statistics, 2014. CA Cancer J Clin. 2014;64(4):252-71. https://doi.org/10.3322/caac.21235

5. Aoki M, Fujisaka $Y$, Tokioka $S$, Hirai $A$, Henmi $Y$, Inoue $Y$, et al. Small-cell Small-cell Lung Cancer in a Young Adult Nonsmoking Patient with Ectopic Adrenocorticotropin (ACTH) Production. Intern Med. 2016;55(10):1337-9. https://doi.org/10.2169/ internalmedicine.55.6139

6. Bourke W, Milstein D, Giura R, Donghi M, Luisetti M, Rubin AH, et al. Lung cancer in young adults. Chest. 1992;102(6):1723-9. https:// doi.org/10.1378/chest.102.6.1723

7. McDuffie HH, Klaassen DJ, Dosman JA. Characteristics of patients with primary lung cancer diagnosed at age 50 or younger. Chest. 1989;96(6):1298-1301. https://doi.org/10.1378/chest.96.6.1298

8. Francisci S, Minicozzi P, Pierannunzio D, Ardanaz E, Eberle A, Grimsrud TK, et al. Survival patterns in lung and pleural cancer in Europe 1999-2007: Results from the EUROCARE-5 study. Eur J Cancer. 2015;51(15):2242-2253. https://doi.org/10.1016/j. ejca.2015.07.033

9. Allemani C, Weir HK, Carreira H, Harewood R, Spika D, Wang XS, et al. Global surveillance of cancer survival 1995-2009: analysis of individual data for 25,676,887 patients from 279 population-based registries in 67 countries (CONCORD-2). Lancet. 2015;385(9972):977-1010. Erratum in: Lancet. 2015;385(9972):946. https://doi.org/10.1016/S0140-6736(14)62038-9

10. Lombardi EM, Prado GF, Santos Ude P, Fernandes FL. Women and smoking: risks, impacts, and challenges. J Bras Pneumol. 2011;37(1):118-28. https://doi.org/10.1590/S180637132011000100017

11. Novaes FT, Cataneo DC, Ruiz Junior RL, Defaveri J, Michelin OC, Cataneo AJ. Lung cancer: histology, staging, treatment and survival. J Bras Pneumol. 2008:34(8):595-600. https://doi. org/10.1590/S1806-37132008000800009

12. Arnold BN, Thomas DC, Rosen JE, Salazar MC, Blasberg JD,
Boffa DJ, Detterbeck FC, Kim AW. Lung Cancer in the Very Young: Treatment and Survival in the National Cancer Data Base. J Thoracic Oncol. 2016;11(7):1121-31. https://doi.org/10.1016/f. jtho.2016.03.023

13. Siegel RL, Miller, KD Jemal A. Cancer statistics, 2016. CA Cancer J Clin. 2016;66(1):7-30. https://doi.org/10.3322/caac.21332

14. Eriksen, MP, Mackay J, Schluger N, Islami F, Drope J. The Tobacco Atlas. 5th edition. Atlanta (GA): The American Cancer Society: 2015

15. Malta DC, Moura EC, Silva SA, Oliveira PP, Silva VL. Prevalence of smoking among adults residing in the Federal District of Brasilia and in the state capitals of Brazil, 2008. J Bras Pneumol. 2010;36(1):7583. https://doi.org/10.1590/S1806-37132010000100013

16. World Health Organization [homepage on the Internet] Geneva: WHO [cited 2016 Jan 15]. WHO global report on trends in prevalence of tobacco smoking 2015. [Adobe Acrobat document, 359p.]. Available from: http://apps.who.int/iris/ bitstream/10665/156262/1/9789241564922_eng.pdf

17. Instituto Nacional do Câncer [homepage on the Internet]. Rio de Janeiro: INCA; [updated 2016 Jul 28; cited 2016 Sep 5]. Observatório da Política Nacional de Controle do Tabaco; labout 18 screens]. Available from: http://www2.inca.gov.br/wps/wcm/ connect/observatorio_controle_tabaco/site/home/dados_numeros/ prevalencia-de-tabagismo

18. Pereira CF, de Vargas D. Profile of women who carried out smoking cessation treatment: a systematic review. Rev Saude Publica. 2015;49:40. https://doi.org/10.1590/S0034-8910.2015049005783

19. McKee SA, Maciejewski PK, Falba T, Mazure CM. Sex differences in the effects of stressful life events on changes in smoking status. Addiction. 2003:98(6):847-55. https://doi.org/10.1046/.1360-0443.2003.00408.x

20. Bohadana A, Nilsson F, Rasmussen T, Martinet Y. Gender differences in quit rates following smoking cessation with combination nicotine therapy: influence of baseline smoking behavior. Nicotine Tob Res. 2003:5(1):111-6. https://doi. org/10.1080/1462220021000060482

21. Alexander M, Evans SM, Stirling RG, Wolfe R, Officer $A$ MacManus $M$, et al. The Influence of Comorbidity and the Simplified Comorbidity Score on Overall Survival in Non-Small Cell Lung Cancer-A Prospective Cohort Study. J Thorac Oncol. 2016;11(5):748-57. https://doi.org/10.1016/j.jtho.2016.01.016

22. Pakzad R, Mohammadian-Hafshejani A, Ghoncheh M, Pakzad I, Salehiniya $\mathrm{H}$. The incidence and mortality of lung cancer and their relationship to development in Asia. Transl Lung Cancer Res. 2015;4(6):763-74.

23. Sun S, Schiller JH, Gazdar AF. Lung cancer in never smokers-a different disease. Nat Rev Cancer. 2007;7(10):778-90. https://doi. org/10.1038/nrc2190 
24. Subramanian J, Govindan R. Lung cancer in never smokers: a review. J Clin Oncol. 2007;25(5):561-70. https://doi.org/10.1200/ JCO.2006.06.8015

25. Global Burden of Disease Cancer Collaboration, Fitzmaurice C Allen C, Barber RM, Barregard L, Bhutta ZA, et al. Global, Regional, and National Cancer Incidence, Mortality, Years of Life Lost, Years Lived With Disability, and Disability-Adjusted Life-years for 32 Cancer Groups, 1990 to 2015: A Systematic Analysis for the Global
Burden of Disease Study. JAMA Oncol. 2017;3(4):524-548. https:// doi.org/10.1001/jamaoncol.2016.5688

26. Repetto L, Luciani A. Cancer treatment in elderly patients: evidence and clinical research [Article in Italian]. Recenti Prog Med. 2015;106(1):23-7.

27. Froesch P, Martucci F, Györik S, Dutly AE, Cafarotti S. Management of non-small cell lung cancer in the elderly. Eur $\mathrm{J}$ Intern Med. 2014;25(10):888-94. https://doi.org/10.1016/j.ejim.2014.10.024 